\title{
RETENÇÃO E EVASÃO NO ENSINO SUPERIOR PÚBLICO: ESTUDO DE CASO EM UM CURSO NOTURNO DE ODONTOLOGIA
}

\author{
Juliana Maciel de Souza Lamers* \\ Universidade Federal do Rio Grande do Sul (UFRGS), Porto Alegre - RS, Brasil \\ Bettina Steren dos Santos** \\ Pontifícia Universidade Católica do Rio Grande do Sul (PUC-RS), Porto Alegre - RS, Brasil \\ Ramona Fernanda Ceriotti Toassi”* \\ Universidade Federal do Rio Grande do Sul (UFRGS), Porto Alegre - RS, Brasil
}

RESUMO: Este artigo analisa a situação acadêmica e o significado das experiências de retenção e evasão na perspectiva de estudantes e professores do curso noturno de Odontologia, criado a partir do REUNI, em uma universidade federal no Sul do Brasil. Trata-se de estudo de caso, predominantemente qualitativo, realizado pela análise documental da situação acadêmica de estudantes (2010-2014) e por entrevistas semiestruturadas com estudantes e professores ( $\mathrm{n}=24)$. Dos 121 estudantes, 49 estavam em situação de retenção, especialmente por reprovação, e 24 evadiram do curso. A partir da análise das entrevistas, emergiram cinco categorias de significado de retenção e evasão: chegada e adaptação à universidade, conciliação trabalho-estudo, vivências em sala de aula, avaliação da aprendizagem e papel da instituição de ensino na permanência dos estudantes. Ações que contemplem as percepções de gestores, professores e estudantes devem ser consideradas para promover o sucesso acadêmico e a permanência dos estudantes no curso até sua conclusão.

Palavras-chave: Educação superior. Educação em odontologia. Evasão escolar. Políticas públicas.

http://dx.doi.org/10.1590/0102-4698154730

Elocation-id - e 154730

"Doutoranda no Programa de Pós-Graduação em Educação da Universidade Federal do Rio Grande do Sul (UFRGS). Mestre em Ensino na Saúde pela UFRGS. Técnica em Assuntos Educacionais e Coordenadora do Núcleo Acadêmico da Faculdade de Odontologia da UFRGS. Grupos de Pesquisa: Educação na Saúde Bucal e Núcleo de Estudos de Política e Gestão da Educação. E-mail: < juli.desouza@ufrgs.br > .

"Doutora. Decana Associada da Escola de Humanidades da Pontifícia Universidade Católica do Rio Grande do Sul (PUC-RS). Grupo de Pesquisa: PROMOT (Processos Motivacionais em Contextos Educativos). E-mail: < bettina@pucrs.br>.

"*”Doutora em Educação pela Pontifícia Universidade Católica do Rio Grande do Sul (PUC-RS). Professora Pesquisadora e Coordenadora Substituta do Programa de Pós-Graduação em Ensino na Saúde (PPG EnSau) da Universidade Federal do Rio Grande do Sul (UFRGS). Grupo de Pesquisa: Educação na Saúde Bucal. E-mail: < ramona.fernanda@ufrgs.br >. 


\section{RETENTION AND DROPOUT ON PUBLIC HIGHER EDUCATION: A CASE REPORT OF A DENTISTRY-EVENING COURSE}

ABSTRACT: This paper analyzes the academic situation and the meaning of retention/dropout experiences from a student/professor perspective at a Dentistry-evening course created by REUNI at a Federal University in South of Brazil. This case study is qualitative in essence and was performed based on documental analysis of academic status of students between 2010 to 2014 and by structured interviews with students and teachers $(\mathrm{n}=24)$. The survey has involved 121 students and has indicated 49 students were on retention and 24 dropped out the course. Five categories have emerged from interviews: the arrival and adaptation to higher education; the imbalance between job vs school; the experiences of students at classroom; evaluation of the learning process; and the role of the Institution in the permanence of students in the Dentistry-evening course. Actions including the opinion of managers, of teachers and students are essential in order to achieve the academic success and the maintenance of students until the accomplishment of the course.

Keywords: Higher education. Dental education. Student dropout. Public policies.

\section{DAS DIRETRIZES CURRICULARES NACIONAIS À POLÍTICA DE AMPLIAC̣̃̃O E REESTRUTURAÇÃO DO ENSINO PÚBLICO SUPERIOR: O QUE MUDOU NOS CURSOS DE ODONTOLOGIA NO BRASIL?}

O ensino superior no Brasil tem se caracterizado por intensas transformações que vão desde mudanças e inovações na organização dos currículos até novas formas de oferecimento de cursos de graduação e ampliação de vagas (MACEDO et al., 2005; TRIGUEIRO, 2003).

Para os cursos da área da saúde, destacando-se a Odontologia, o estabelecimento de Diretrizes Curriculares Nacionais (DCN) representou uma mudança paradigmática no perfil da formação, a qual passou a priorizar o aprendizado por competências, orientado aos problemas mais relevantes da sociedade, comprometido com a concretização dos princípios do movimento da Reforma Sanitária Brasileira e do Sistema Único de Saúde (FEUERWERKER; ALMEIDA, 2004). Além disso, as diretrizes enfatizaram a desconstrução da fragmentação do cuidado em saúde e a pouca ou nenhuma conexão entre o mundo real e a experiência vivida na graduação (FAGUNDES; BURNHAM, 2005).

Nesse contexto, o tema da inovação curricular constituiu-se uma tendência para os estudos sobre currículos em saúde no Brasil, 
mostrando propostas de mudanças ou de processos relacionados à implantação de projetos pedagógicos e currículos inovadores, integrados e interdisciplinares (BRAID; MACHADO; ARANHA, 2012).

O currículo inovador deveria articular um conjunto de alterações capazes de afetar pontos-chave e eixos constitutivos da organização do ensino universitário, além de contribuir para superar o paradigma conservador que tem caracterizado o ensino nas instituições superiores (KELLER-FRANCO; MASETTO, 2012; MASETTTO, 2004). É um currículo que não se limita a um corpo de conhecimentos, mas que cria em torno de si campos de ação diversos com múltiplos agentes e possibilidades práticas (SACRISTÁN, 2000).

Entendendo o caráter aberto da inovação, capaz de adotar formas e significados conforme os contextos em que se insere, a Odontologia deu início ao processo de elaboração de projetos pedagógicos e reformulações curriculares para contemplar a formação de um egresso com perfil generalista, humanista, crítico, reflexivo, capaz de atuar em diferentes níveis de atenção à saúde e apto ao trabalho em equipe multiprofissional (TOASSI et al., 2012; MORITA; KRIGER, 2004; BRASIL, 2002).

$\mathrm{Na}$ mesma perspectiva de avanço na educação superior, o governo federal propôs ações de ampliação do acesso a essa etapa de ensino no país, como a oferta de vagas em educação a distância pela Universidade Aberta do Brasil (UAB), o projeto Universidade Para Todos (ProUni), a regulamentação do Financiamento ao Estudante de Ensino Superior (FIES) e o Programa de Apoio a Planos de Reestruturação e Expansão das Universidades Federais (REUNI). Esse conjunto de ações retoma a meta de ampliar o acesso ao Ensino Superior para jovens de 18 a 24 anos, prevista no Plano Nacional de Educação de 2001 (SANTOS, 2009).

Proposto em 2007, o REUNI caracteriza-se como a mais recente política de ampliação e reestruturação do ensino público superior no âmbito federal (BRASIL, 2007). Ele é entendido como uma das estratégias para reduzir as desigualdades sociais, promover a inclusão social e melhorar a qualidade do ensino no sistema público de educação superior (ROBERTO, 2011).

Entre as dimensões apontadas pelo REUNI, destaca-se a ampliação da oferta de educação pública superior, com o aumento de vagas para ingresso na universidade federal, especialmente no período noturno (BRASIL, 2007). Tal enfoque do REUNI tem justificativa relevante para o Brasil, uma vez que, tradicionalmente, as instituições de ensino superior, em especial as instituições públicas, eram 
conhecidas pelo caráter diurno e pela rigidez seriada, estabelecendose como espaços ocupados por aqueles que não possuíam vínculo com o mundo do trabalho (ARROYO, 1991).

Mais do que uma preocupação governamental, a ampliação do acesso à universidade envolve a sociedade contemporânea, principalmente no que se refere ao aumento de vagas que permita a equidade e a formação de qualidade, com ênfase na responsabilidade social (NEVES; RAIZER; FACHINET'TO, 2007). O investimento nas instituições federais justifica-se ainda mais, na medida em que estas concentram maior número de pesquisadores, com corpo docente composto na sua maioria por doutores, com grande potencial para oferecer ensino, pesquisa e extensão de qualidade no país (COSTA; COSTA; BARBOSA, 2013).

Impulsionada pela reestruturação curricular de 2005, baseada nas DCN (UFRGS, 2014a) e diante do cenário favorável de expansão e reestruturação do ensino superior estimulado pelo REUNI, a Universidade Federal do Rio Grande do Sul (UFRGS) iniciou, no segundo semestre de 2010, um curso de Odontologia integralmente realizado no período noturno.

A proposta, até então inovadora para a Universidade, trouxe a possibilidade da inserção do estudante trabalhador no Ensino Superior e, de modo especial, no curso de Odontologia, atendendo à demanda de quem desenvolve suas atividades profissionais durante o dia e dispõe somente do horário noturno para realizar sua formação acadêmica.

O projeto pedagógico do curso noturno foi embasado no programa do curso diurno de Odontologia da mesma instituição, contemplando igual carga horária total (5040 horas), créditos obrigatórios (312 créditos), eletivos (8 créditos) e complementares (16 créditos). Como suas atividades de ensino obrigatórias acontecem exclusivamente no turno da noite, o curso contempla uma carga horária de 20 horas semanais de atividades obrigatórias presenciais, o que justifica sua duração de 16 semestres (UFRGS, 2014b).

Anualmente, 30 vagas são oferecidas para ingresso no curso noturno de Odontologia, com início no segundo semestre do ano. Para o curso diurno são oferecidas 44 vagas por semestre. $\mathrm{O}$ candidato deve fazer a opção pelo curso noturno ou diurno no ato da inscrição ao processo seletivo, não sendo possível cursar disciplinas obrigatórias de um turno ou outro durante a formação. A troca de curso (do noturno para o diurno ou o contrário) pode ocorrer somente mediante a realização de novo processo seletivo.

Apesar do inegável avanço em relação à oportunidade do acesso do estudante trabalhador ao Ensino Superior, seria um 
reducionismo considerar indiscriminadamente o acesso como sucesso escolar (ZAGO, 2006).

Entendendo que o sucesso acadêmico deva ir além do acesso ao Ensino Superior, o presente estudo se propôs a analisar a situação acadêmica dos estudantes do curso noturno de Odontologia da UFRGS, compreendendo o significado das experiências de retenção e evasão na perspectiva dos estudantes e professores do curso.

O estudo justifica-se pela importância que possui a criação de um curso noturno de Odontologia em uma instituição pública de ensino como a UFRGS - reconhecida por sua qualidade de ensino, pesquisa e extensão e que possui um curso de Odontologia em período integral com mais de um século de tradição universitária e excelência acadêmica. A intenção que o move vai além da constatação acerca da democratização do acesso, buscando elementos para consolidar a permanência do estudante do curso noturno no ensino superior.

\section{PERCURSO METODOLÓGICO}

A pesquisa fundamentou-se nos preceitos metodológicos da pesquisa qualitativa, caracterizando-se como um estudo de caso (YIN, 2010). O campo de investigação foi o curso noturno de graduação em Odontologia da UFRGS ${ }^{1}$.

Para responder aos objetivos propostos, a coleta de dados aconteceu em dois momentos:

$1^{\circ}$ momento-Identificação da situação acadêmica dos estudantes: análise de documentos relativos ao período de ingresso, trancamento de matrícula e histórico escolar de todos os estudantes que ingressaram no curso noturno de Odontologia de 2010 a fevereiro de 2014 ( $n=121)$.

As variáveis investigadas foram: seriação aconselhada, retenção por reprovação/trancamento e evasão. Quando houve reprovação, foram identificadas as disciplinas em que a reprovação aconteceu.

A seriação aconselhada de um curso, de acordo com a legislação da universidade (UFRGS, 2003), é definida como a sequência de etapas nas quais são apresentadas disciplinas oferecidas em um mesmo período letivo. Nesse sentido, a retenção observada neste estudo é entendida como a mudança na seriação aconselhada do estudante a partir daquela definida no semestre de ingresso, em virtude de reprovação, cancelamento, trancamento de matrícula ou afastamento, fazendo com que o estudante precise de mais tempo para concluir o curso.

A evasão é um fenômeno que pode se apresentar de diferentes formas, de acordo com: a instância de evasão (curso, 
instituição ou sistema), a autoria da decisão de evasão (do estudante ou desligamento pela instituição), a forma de evasão (abandono, transferência, desligamento), o período de evasão (se temporária ou definitiva) e o momento do curso em que a evasão acontece (anos iniciais, intermediários ou finais) (POLYDORO, 2001). Neste estudo a evasão é entendida como a saída do estudante do curso noturno de Odontologia por abandono, transferência interna ou desligamento para ingresso por vestibular em outro curso (mesmo que o outro curso seja o diurno de Odontologia).

Os dados obtidos foram digitados no software IBM SPSS (Statistical Package for the Social Sciences) para $W^{\text {indows }}{ }^{2}$ e analisados por meio da distribuição de frequências para detectar o número de observações em cada variável do conjunto de dados.

$2^{\circ}$ momento - Significado das experiências de retenção e evasão na perspectiva de estudantes e professores: estudantes em situação de retenção e que haviam evadido do curso foram convidados a participar de uma entrevista semiestruturada, assim como os professores das disciplinas do curso noturno de Odontologia em que houve a reprovação (amostra intencional). O contato inicial foi realizado por mensagem por meio de correio eletrônico.

As entrevistas foram realizadas na Faculdade de Odontologia, seguindo um roteiro previamente testado, de forma individual, gravadas em áudio, após o consentimento do(a) entrevistado(a) e assinatura do Termo de Consentimento Livre e Esclarecido. Todas as gravações foram transcritas na íntegra e enviadas, posteriormente, por correio eletrônico aos entrevistados para sua revisão. Foram gravadas aproximadamente 20 horas de entrevistas.

O roteiro da entrevista contemplou questões relacionadas ao perfil do entrevistado (idade, sexo, trabalho, carga horária e Ensino Médio em escola pública ou privada para estudantes, e idade, sexo e regime de trabalho para professores), aos motivos de escolha do curso, e à situação de retenção (motivos, apoio, sentimento e maneiras de se evitar) e de evasão (quando decidiu sair do curso, como foi esta decisão, motivos, sentimentos e como poderia evitar a saída).

$\mathrm{Na}$ entrevista semiestruturada, os tópicos do roteiro elaborado funcionam apenas como lembretes, devendo, na medida do possível, serem memorizados pelo pesquisador quando está em campo. O roteiro utilizado na pesquisa serviu de orientação e guia para o andamento da interlocução e foi construído de forma a permitir flexibilidade nas conversas e a absorção de novos temas e questões trazidas pelo interlocutor e entendidas como relevantes para o estudo, conforme recomendado por Minayo (2009). 
O tamanho da amostra foi definido pelo critério da saturação (FONTANELLA; RICAS; TURATO, 2008), ou seja, quando se entendeu que novas falas passaram a ter acréscimos pouco significativos em vista dos objetivos propostos pela pesquisa e tornam-se expressivamente repetitivas, decidiu-se pelo encerramento das entrevistas.

$\mathrm{Na}$ medida em que os estudantes recebiam o convite e participavam das entrevistas, conversavam com seus colegas sobre o propósito do estudo e outros estudantes se interessavam e procuravam os pesquisadores para contribuir com seus relatos.

Ao final, foram entrevistados 16 estudantes e oito professores $(\mathrm{n}=24)$, conforme esquema apresentado na Figura 1.

O material textual obtido nas entrevistas, após a transcrição, foi importado para o software ATLAS.ti (Visual Qualitative Data Analysis) ${ }^{3}$ interpretado por meio da análise temática de conteúdo proposta por Bardin (2011).

FIGURA 1 - Caracterização dos estudantes e professores do curso noturno de Odontologia/ UFRGS que participaram das entrevistas

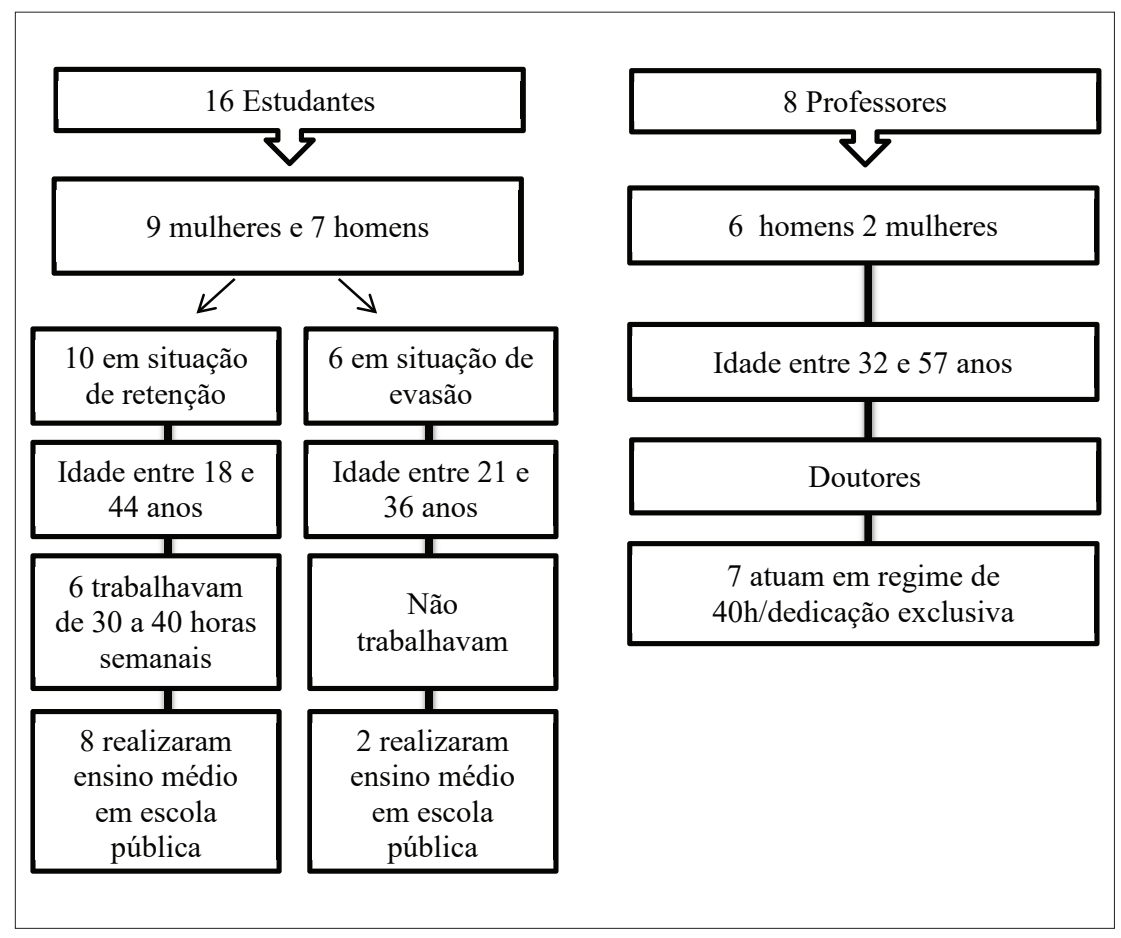

Fonte: Elaboração pelos autores deste artigo. 


\section{SITUAÇÃO ACADÊMICA DOS ESTUDANTES DO CURSO NOTURNO DE ODONTOLOGIA: SERIAC̣ÃO ACONSELHADA, RETENÇÃO E EVASÃO}

A retenção e a evasão no Ensino Superior têm se constituído como questões relevantes na maioria dos países, desde os europeus até os da América Latina, demonstrando que o abandono e as sucessivas reprovações são fenômenos complexos e multidimensionais que constituem uma problemática educativa e social (VIDALES, 2009).

Ainda que os cursos de graduação em Odontologia no Brasil não apresentem índices de abandono tão elevados quando comparados a outros cursos universitários, a temática exige atenção, pois constitui investimento público que deixa de gerar benefícios - no caso das instituições públicas de Ensino Superior - além de prejuízo para cada estudante que abandona, reprova ou necessita de mais tempo do que o indicado para conclusão de seu curso (SALIBA et al., 2006).

A análise da situação acadêmica dos 121 estudantes do curso noturno de Odontologia da UFRGS, no período de 2010 a fevereiro de 2014, pode ser observada na Figura 2.

Destaca-se que 49 dos 121 estudantes estavam fora da seriação aconselhada (40,5\% de retenção), sendo a maioria deles somente por reprovação em uma ou mais disciplinas $(n=33)$. O percentual de evasão observado foi de 19,9\% ( $\mathrm{n}=24)$. Dos 24 estudantes evadidos, 19 cursam Odontologia no curso diurno da mesma instituição.

Há poucos relatos na literatura que tratam, de forma específica, da retenção e da evasão no ensino superior em Odontologia no Brasil.

Estudo realizado em uma universidade pública de São Paulo apontou um percentual de reprovação no curso de Odontologia de 1,6\% no período de 1992-2002 (SALIBA et al., 2006). Esse percentual de retenção por reprovação foi bem inferior aos $27,3 \%$ encontrados no curso noturno de Odontologia da UFRGS.

Já em relação à evasão, o índice de 19,9\% de estudantes evadidos do curso noturno também foi superior ao identificado por outros estudos em cursos de Odontologia do Brasil - 9\% em universidades públicas na década de 90 (ASSOCIAÇÃO NACIONAL DOS DIRIGENTES DAS INSTITUIÇÕES FEDERAIS DE ENSINO SUPERIOR, 1996); 11\% em universidades brasileiras entre 2000 e 2005 (SILVA FILHO et al., 2007); 2,2\% na Faculdade de Odontologia de Araçatuba-UNESP entre 1992 e 2002 (SALIBA et al., 2006) e 2\% no Centro de Ciências da Saúde da Universidade Federal do Espírito Santo, entre 2001 e 2007 (GOMES et al., 2010). 
FIGURA 2 - Situação acadêmica dos estudantes ingressantes do curso noturno de Odontologia/UFRGS, 2010 a fevereiro de 2014

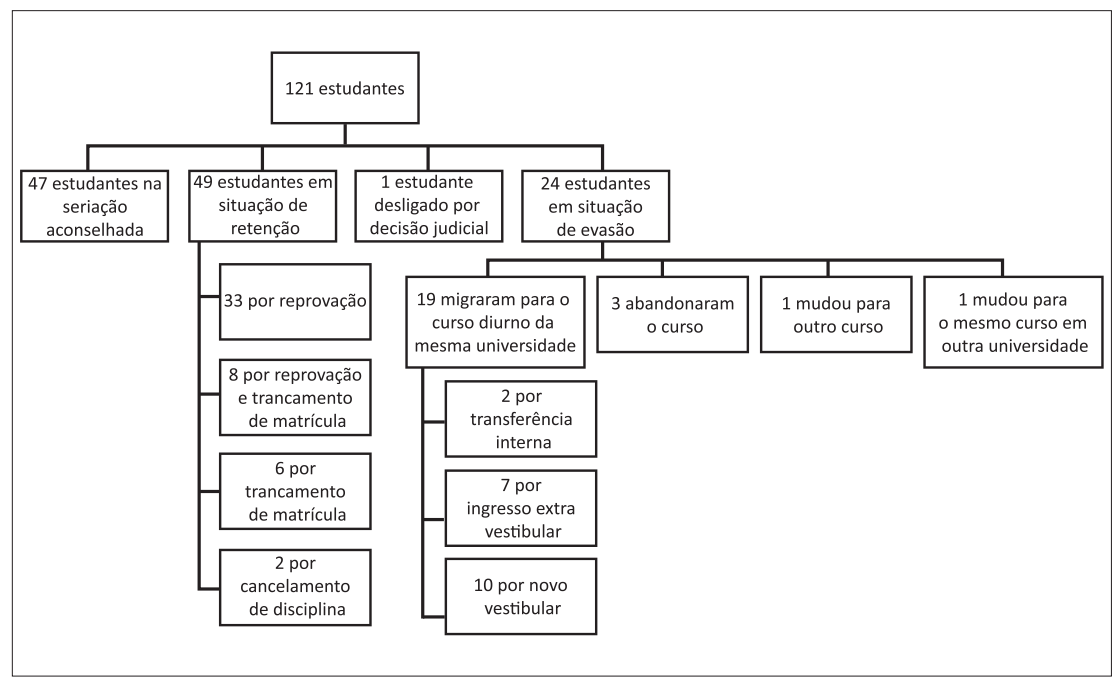

Fonte: Elaboração pelos autores deste artigo.

$\mathrm{Na}$ UFRGS, cenário deste estudo, resultados de pesquisa realizada sobre a evasão em todos os cursos da área da saúde, entre 2008 e 2010, mostrou que o curso de Odontologia tinha o menor percentual de evasão observado $(0,9 \%)$ (BUENO et al., 2011). Naquele período, a instituição oferecia o curso de Odontologia somente em período integral. A primeira turma do curso noturno de Odontologia ingressou no segundo semestre de 2010.

Considerando que a maioria dos estudantes que evadiu do curso noturno não abandonou nem a universidade e nem a formação em Odontologia, o índice de evasão observado está contemplado na categoria de 'evasão aparente', aquela em que o estudante muda de um curso para outro, permanecendo no Ensino Superior. A 'evasão real' seria aquela em que o estudante desiste de cursar o Ensino Superior (CARDOSO, 2008).

Mesmo permanecendo na universidade, é importante a avaliação da ocorrência de evasão do curso noturno, pois a mudança de curso por parte do estudante gera uma vaga ociosa na instituição, que precisa ser preenchida. "As perdas de estudantes que iniciam, mas não terminam seus cursos são desperdícios sociais, acadêmicos e econômicos" (SILVA FILHO et al., 2007, p. 642). 


\section{COMPREENDENDO O SIGNIFICADO DAS EXPERIÊNCIAS DE RETENÇ̃̃O E EVASÃO NO CURSO NOTURNO DE ODONTOLOGIA: PERCEPÇÃO DE ESTUDANTES E PROFESSORES}

Compreender significa intelectualmente aprender em conjunto, comprehendere, abraçar junto, (o texto e seu contexto, as partes e o todo, o múltiplo e o uno). [...] Compreender inclui, necessariamente, um processo de empatia, de identificação e de projeção. Sempre intersubjetiva, a compreensão pede abertura, simpatia e generosidade. (MORIN, 2000, p. 94-95)

Analisar processos de retenção e evasão de estudantes no Ensino Superior sempre mostra uma complexidade em virtude da existência de diferentes fatores que as determinam, podendo estar relacionadas a questões intrínsecas ou extrínsecas ao estudante, fatores pessoais, familiares e institucionais (FREITAS, 2009; DONOSO; SCHIEFELBEIN, 2007; YEPES et al., 2007).

Ideias, percepções, sentimentos e avaliações dos estudantes e professores entrevistados com relação à retenção e evasão no curso noturno de Odontologia são apresentados em cinco categorias emergentes, como é possível verificar na Figura 3.

FIGURA 3 - Categorias emergentes das falas de estudantes e professores em relação à retenção e à evasão no curso noturno de Odontologia/UFRGS, 2010 a fevereiro de 2014

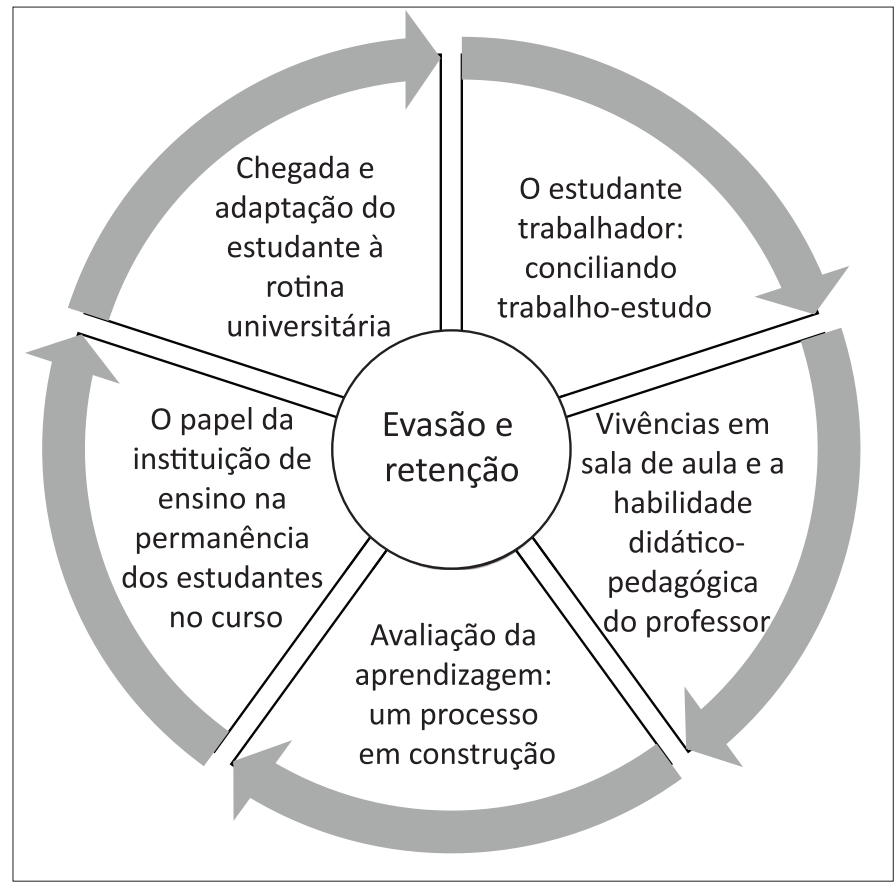

Fonte: Elaboração pelos autores deste artigo. 


\section{Chegada e adaptação do estudante à rotina universitária}

O primeiro ano na universidade caracteriza-se como um período crítico, potencializador de crises e desafios, sendo determinante dos padrões de desenvolvimento do estudante ao longo de sua trajetória universitária (ALMEIDA; SOARES, 2003).

Ao chegarem ao curso noturno de Odontologia, os estudantes sentiram-se afetados pela 'nova' exigência de estudo que caracteriza a rotina universitária, marcada pela grande quantidade de conteúdos em diferentes disciplinas. A diferença entre a rotina de estudos no Ensino Médio e, depois, na universidade, também foi destacada. A forma de estudar foi tida como determinante para o desempenho do estudante nas disciplinas, levando inclusive a uma reprovação e consequente retenção no curso. A solução encontrada pelos estudantes para facilitar o momento inicial de adaptação ao curso focou-se na mudança da forma de organizar sua rotina de estudos.

Eu deixei acumular matéria e não tinha como eu dar contapara as provas finais. Acumulou, dai eu fui mal, eu achei que ia conseguir recuperar na segunda prova e não consegui, até chegar à reprovação. [...] a rotina de estudos muda muito, eu saí direto do colégio, fiquei um ano e depois entrei para a faculdade, então tinha aquela rotina assim, estuda uns dois dias antes, dou uma lida no capitulo e... não dá! [...] Comecei a me organizar melhor, porque é muita matéria e é pouco tempo, e às vezes o que tu vê dentro de sala de aula não é o suficiente, tem que se inteirar sozinho. [...] que não dá para deixar acumular, e isso era normal no colégio, deixar as coisas mais pra última hora. Isso está sendo uma adaptação, assim, se programar, se organizar, ter cronograma de estudos, ter cronograma dos trabalhos, para fazer com uma certa antecedência para não dar errado. (Estudante 5)

No estudo realizado por Teixeira e colaboradores (2008), sobre a experiência de adaptação de ingressantes de diferentes cursos à universidade, os estudantes expressaram a necessidade de assumir uma postura ativa frente à aprendizagem, buscando formas de aprender e oportunidades além das aulas. Eles afirmaram que o ingresso na universidade acarretou mudanças de comportamento que repercutiram na vida pessoal e profissional, o que também foi relatado pelos estudantes do curso noturno de Odontologia da UFRGS.

Os professores, por sua vez, observaram que o maior espaço de tempo entre o término do Ensino Médio e o ingresso no Ensino Superior também constituiu um desafio, uma vez que os estudantes que estavam há mais tempo longe da escola apresentaram dificuldades para relembrar conhecimentos do ensino básico que são necessários à sua formação de cirurgião-dentista.

[...] muitos alunos têm dificuldade, especialmente nos primeiros semestres, quando nós tínhamos alunos de mais idade, talvez atéporque eles já tenham esquecido o que aprenderam, 
já faz tanto tempo que fižeram o ensino médio, e a [...] área que requer a base de química, de física, de matemática, precisa desses conbecimentos um pouco mais disponiveis, um pouco mais próximos, um pouco mais presentes. Eu percebo bastante dificuldade com os alunos que fizeram o ensino médio há mais tempo em relação a isso. (Professor 8)

Os mesmos problemas foram verificados por Silva et al. (2010) ao investigarem fatores que influenciavam o desempenho acadêmico entre estudantes de Odontologia da Universidade Federal de Goiás. Os resultados mostraram um melhor desempenho relacionado ao menor tempo entre a conclusão do Ensino Médio e o ingresso dos estudantes na graduação. Já o estudo de Vargas e Paula (2013) sobre a inclusão do estudante trabalhador na universidade verificou que, entre os professores, foi recorrente a percepção de que o ensino básico não possibilitou a base necessária para a continuidade dos estudos no Ensino Superior e considerou que a fragilidade do ensino básico é, sim, um dos fatores condicionantes para o desempenho acadêmico, mas não é o único. $\mathrm{O}$ desempenho no ensino básico também foi citado por coordenadores de curso da Universidade Federal do Mato Grosso - campus Cuiabá como fator de interferência no desempenho na graduação, podendo se refletir em evasão (VELOSO; ALMEIDA, 2002).

Outra questão destacada pelos estudantes que passaram por reprovação no curso de Odontologia foi a expectativa de vivências em atividades curriculares práticas relacionadas com a profissão, desde o início do curso, o que não foi percebido, levando o estudante a um distanciamento do curso.

[...] às vezes en acho que essa parte mais prática, mais dinâmica da Odontologia falte e talvez isso faça com que eu me distancie, fique em cima só de livro, faz̧endo que a cadeira daquele semestre me pegue. [...] realmente, para mim foi bem maçante essas partes mais teóricas. (Estudante 5)

Cunha e Carrilho (2005) reforçam a importância das vivências dos estudantes no primeiro ano do curso superior, tanto em nível pessoal quanto em termos de realização acadêmica, o que pode afetar o desempenho dos estudantes no curso.

\section{O estudante trabalhador: conciliando trabalho e estudo}

O Projeto Pedagógico do curso noturno de Odontologia da UFRGS prevê a inserção do estudante trabalhador na universidade na formação em saúde. A sua meta é o desenvolvimento de habilidades e competências para trabalhar em equipe, bem como fazer análise crítica do seu desempenho individual e na equipe, contribuindo para a melhoria da sua formação profissional e dos serviços de saúde (UFRGS, 2014b). 
A literatura aponta que conciliar a condição de estudante e de trabalhador é considerado um fator complicador para a permanência e a conclusão do curso, diferentemente da condição de estudante de tempo integral, que tem grande disponibilidade de tempo para realizar seus estudos (VARGAS; PAULA, 2013; ARROYO, 1991).

Para os estudantes que exerciam atividades profissionais formais durante o dia, o cansaço, o sono e até o esgotamento após o dia de trabalho, além da falta de tempo para estudar, foram fatores que interferiram no desempenho das disciplinas cursadas.

Acho que eu poderia ir melhor, mas dentro do que eu consigo, dos meus horários, eu procuro sempre estar lendo... sobrou um intervalo no meu trabalho eu procuro ler, eu acho que eu poderia, se eu tivesse mais tempo disponivel. (Estudante 12)

Os professores também percebiam, entre os estudantes que trabalhavam, a dificuldade relacionada ao tempo para dedicação aos estudos e o cansaço, a diminuição da concentração com a aproximação do horário de término da aula do turno da noite, influenciando o rendimento da turma.

Eu chamo eles bastante para a aula, mas tem que ser observado é que ali pelas 21:30, 21:20, a turma já está aérea, alguns com aquela cara de sono, e aí a coisa fica bem complicada, e o rendimento cai bastante a partir de 21:20, 21:30... [...] Chega uma hora que eles não rendem mais. [...]. (Professor 4)

Apesar da falta de tempo do estudante trabalhador, os professores reconheceram a atenção que esse estudante dedica às aulas e perceberam que ele valorizava o momento presencial das atividades de ensino durante sua permanência em sala de aula.

[...] Por não terem tempo para estudar em outros momentos, esses alunos estão tentando prestar atenção o máximo possivel. Aluno que trabalha, que tem uma jornada de oito horas por dia, que está lá no batente e depois vai ainda estudar à noite, a gente percebe claramente o desempenho desse aluno durante a aula, ele presta muito mais atenção naquilo que o professor fala, porque ele sabe que aquele é o único momento que ele vai ter condição de acessar o conteúdo, porque final de semana tem família, tem outras atividades para fazer e também precisa descansar. (Professor 1)

Soares e Sampaio (2013) questionaram o preparo da Universidade para acolher o estudante trabalhador. Em sua pesquisa, estudantes destacaram que o vínculo com o trabalho não atrapalha os estudos, porém exige maior organização, sendo que o resultado acadêmico vai depender muito do esforço e da organização pessoal. A condição de estudante trabalhador vai além da frequência às aulas ou da realização de estudos ou tarefas, demandando a formação de 
vínculos, diálogos e a realização de tarefas com outros estudantes. Tais atividades demandam tempo e se tornam um desafio maior para aqueles que precisam repartir o tempo entre a vida profissional, familiar e de estudante (COULON, 2008, citado por SOARES; SAMPAIO, 2013).

Para os professores, a ideia de conciliar trabalho e estudo e a meta de ter um prazo para concluir a formação e ingressar no mercado de trabalho podem ser fatores de motivação para melhorar o desempenho no curso e os estudantes deveriam se esforçar ao máximo para conseguir isso. Os professores percebem que o estudante trabalhador sabe o que procura no curso noturno de Odontologia, tem um objetivo bem estabelecido desde o início da graduação.

[...] se percebe claramente que o estudante que trabalha sabe o porquê está fazendo o curso. Ele tem como objetivo seguir a carreira odontológica, realização de vida ou qualquer que seja a razãa, mas ele tem objetivo específico. (Professor 1)

Para o estudante-trabalhador, a obtenção do diploma de ensino superior poderá traduzir-se em uma inserção em nível mais elevado no mercado de trabalho, levando a uma melhor condição de vida e a uma mudança na situação socioeconômica (TERRIBILI FILHO, 2008). Os conhecimentos agregados durante o curso de graduação, as vivências pessoais e as relações construídas com colegas e professores também constituem aprendizagens que prepararão o estudante-trabalhador para ingressar no mercado de trabalho na sua área de formação (TERRIBILI FILHO; NERY, 2009).

Outro aspecto importante a ser discutido é a perspectiva dos estudantes que também são trabalhadores, conseguem ingressar no Ensino Superior e ter acesso ao curso de Odontologia da UFRGS enquanto grupo social subalterno à universidade pública.

Os grupos desiguais têm estado na pauta das preocupações do Estado, o qual propõe alternativas compensatórias e redistributivas para coletivos desiguais sem identidade, sem rosto. Os desiguais são pensados como problemas. Porém, as alternativas propostas para incluir os desiguais são pensadas como pontes, passarelas que somente poderão ser atravessadas por aqueles que se dedicarem, demostrarem esforço, merecimento, êxito. Tais políticas usualmente desconsideram que as desigualdades são produzidas pelas "condições de viver, de emprego, de sobrevivência, de exploração no trabalho" (ARROYO, 2010, p. 1390).

Pensando na redução das desigualdades é fundamental que as instituições de Ensino Superior ampliem a presença de pessoas com diferentes origens e condições sociais em seus espaços educativos, "tornando-as mais plurais e diferenciadas, social e culturalmente" (SCHWARTZMAN, 2008, p. 23). 
A ampliação do acesso à educação superior se deu fortemente a partir do REUNI. Já a diversificação do acesso trata-se de pauta da política de ações afirmativas (BRASIL, 2012). Porém, as vagas públicas oferecidas em período noturno ainda estão fortemente concentradas nos cursos das áreas de Ciências Humanas, de modo especial, na Educação (BITTAR; ALMEIDA; VELOSO, 2008; BARREIRO; TERRIBILLI FILHO, 2007).

Observa-se que as oportunidades de o estudante trabalhador ter acesso a cursos de outras áreas, como a da saúde, por exemplo, ainda são menores no ensino público. A diferença de oferta de vagas entre as áreas de conhecimentos no turno da noite ressalta as limitações que o estudante trabalhador enfrenta na escolha do curso superior. Nesse contexto de estratificação social que existe no ensino superior público da rede federal, poder optar por cursar e concluir Odontologia em uma destacada universidade federal do sul do Brasil torna-se ainda mais relevante para a redução das desigualdades existentes.

\section{Vivências em sala de aula e a habilidade didático-pedagógica do professor}

Ao falarem sobre as vivências em sala de aula, os estudantes observaram que sua participação nas aulas, fazendo comentários e perguntas para esclarecer dúvidas, potencializava a atenção e facilitava o entendimento do assunto estudado, tornando a aula mais dinâmica, aspecto este também observado pelos professores.

Quando comecei a faculdade aqui, eu não perguntava muito [...] só que eu percebi, em algumas perguntas que sairam, que vieram respostas, vieram explicaşões, assim... muito interessantes e proveitosas, ai eu penso 'oh vou perguntar também'! (Estudante 7)

[...] a aula se torna mais legal, mais agradável porque às vez̧es se só tu fala perde muito, se eles [os alunos] perguntam, colaboram, contribuem de alguma forma, não só com perguntas, mas até com opiniões, ai a aula cresce. (Professor 5)

A participação dos estudantes esteve associada à habilidade didático-pedagógica do professor durante as aulas, facilitando, estimulando e demonstrando preocupação com a aprendizagem do grupo. O tempo em sala de aula deve se constituir no que Méndéz (2011, p. 258) chamou de um "tempo de aprendizagem compartilhada", em que o professor entende a importância de adequar os tempos de ensino e de aprendizagem para que esta última tenha melhores chances de acontecer. "Saber dar a todos o tempo adequado de aprender é uma das funções da docência" (ARROYO, 2014, p. 216).

Estudo de Souza e Reinert (2010) com estudantes do curso noturno de Administração em uma instituição pública de Ensino 
Superior mostrou que a didática do professor e os métodos de ensino empregados nas aulas foram uma das causas mais citadas para a insatisfação discente. O papel dos professores e os recursos de aprendizagem também foram fatores significativos para o desempenho de estudantes de Odontologia pesquisados por Al-Amri e colaboradores (2012) em uma instituição pública de Ensino Superior da Arábia Saudita. Cavalcanti e colaboradores (2010) verificaram, em estudantes de Odontologia da Universidade Estadual da Paraíba, que a insatisfação com o corpo docente do curso foi inclusive uma das causas de evasão do Ensino Superior.

O uso de esquemas e fluxogramas do conteúdo abordado e a realização de exercícios e revisões de conteúdos em aula foram estratégias metodológicas de ensino que mobilizaram o interesse do grupo no curso noturno e favoreceram o aprendizado pela clareza com que os conteúdos foram trabalhados pelo professor.

Os esquemas de conexão entre os conteúdos abordados, assim, eu sou uma pessoa muito visual para estudar, então ela trabalhava muito com cores, com fluxograma para a gente entender da onde uma coisa vem, para onde ela vai. E ela explicava várias vežes, tu fazia uma pergunta, ela conseguia pegar na tua pergunta que tu tinha entendido outra coisa e ela já explicava aquilo, ela disponibilizava questionários para a gente fazer, esclarecer dúvidas, en passei a gravar as aulas e ouvir de novo e... bem diferente assim, um linguajar simples[...]. (Estudante 8)

A precisão e a clareza dos conteúdos de aprendizagem, aliadas à apresentação do material utilizado pelo professor também foram considerados aspectos importantes por estudantes universitários da Universidade de Granada, na Espanha, para motivar o estudo, podendo levar a um bom desempenho acadêmico (MORA et al., 2015).

Já aulas expositivas, com tempo prolongado, para uma turma com estudantes que chegam à universidade cansados por conta da jornada de trabalho, ou aulas com a utilização de recursos 'antigos' e pouco atrativos foram consideradas como fatores negativos, desmotivadores, conforme relato do estudante entrevistado:

[...] uma turma cansada do trabalho numa sala à meia luz. e uma voz.por duas horas, isso deve ser repensado. Nesse caso não está sendo priorizado o aprendizado do aluno e sim o cumprimento de cronograma, 'despejando' o conteúdo sem qualquer preocupação que isto seja compreendido. (Estudante 7)

A aula expositiva é largamente utilizada não só por fazer parte da cultura didático-pedagógica, como também por ser econômica, flexível, versátil, rápida e com ênfase no conteúdo, podendo contemplar também recursos atuais como vídeos, imagens, animações. Porém, o estudante que trabalhou durante o dia e enfrentou desafios 
com transporte, trânsito, alimentação, precisa que o professor ofereça algo mais desafiador e motivador em sala de aula, com a utilização de estratégias, técnicas e dinâmicas que complementem a aula expositiva, podendo inclusive relacionar a teoria à sua prática profissional quando já atua na área de formação (TERRIBILI FILHO; NERY, 2009).

Segundo Bordenave e Pereira (2010), a escolha da metodologia a ser empregada em aula deve contemplar desde os objetivos e conteúdos até a interação com a turma de estudantes, para que a aprendizagem ocorra de forma significativa e consistente. Essa escolha deve responder ao objetivo que se pretende alcançar, criando situações e abordando os conteúdos de forma que permita ao estudante vivenciar as experiências necessárias para sua transformação.

Para tanto, é fundamental que a instituição de Ensino Superior invista em uma educação permanente de seus docentes e estimule suas habilidades pedagógicas e investigativas para vincular de maneira mais efetiva os estudantes a seus processos de aprendizagem (FAÚNDEZ; MUÑOZ; CORNEJO, 2012).

\section{Avaliação da aprendizagem: um processo em construção}

Para os estudantes que já passaram por reprovação no curso noturno de Odontologia, a grande quantidade de conteúdos que compõe cada uma das disciplinas e o acúmulo de conteúdo entre as avaliações feitas no semestre interferiram no seu desempenho.

[...] dividir mais a matéria, acho que ele poderia organizar mais, talvez botar em três blocos, porque ficava a grande parte da matéria na primeira prova e duas ou três matérias na segunda, então acho que ficava muita matéria acumulada pra primeira prova, podia ter dividido mais. (Estudante 16)

Os professores, por sua vez, reconheceram a grande quantidade de conteúdos, mas argumentam que os estudantes, de modo geral, não estudam de forma contínua ao longo do semestre, o que acaba influenciando o seu desempenho nas avaliações.

[...] Todo semestre eu aviso 'gente é muita matéria, não adianta estudarem três dias antes, não adianta, tem que começar estudar pelo menos uma semana antes'. [...] reservo um tempo para en dar uma revisão... ou várias vezes en dou revisão. Começo a perguntar coisas e começo a ficar deprimido antes de corrigir a prova. Porque é um silêncio total... dai é a quela coisa, eles não estudaram, pelo menos não ainda o suficiente. (Professor 4)

Outro aspecto destacado na fala dos estudantes foram as avaliações com ênfase na memorização do conteúdo. Tanto estudantes quanto professores ressaltaram a importância de ir além da 'mera' memorização e também entendem que a memorização é 
uma etapa importante para o aprendizado de conteúdos específicos da formação do cirurgião-dentista.

A memória é um importante elemento no processo educativo, sendo necessário considerar o tempo de contato com determinado assunto para que ele seja 'trabalhado' pela memória. Portanto, mais do que planejar situações de aprendizagem para a sala de aula, é necessário planejar o tempo de reflexão sobre essas atividades (ARROYO, 2014).

O processo de avaliação deve, mais do que verificar o que o estudante foi capaz de memorizar, constatar se o estudante é capaz de proceder a análises e sínteses, verificar o nível de compreensão do que foi ensinado e de transferência daquilo que foi aprendido para outras situações (GIL, 2010).

\section{O papel da instituição de ensino na permanência dos estudantes no curso}

Vargas e Paula (2013) entendem como fundamental que a instituição de ensino se prepare para o desafio de oferecer um curso noturno, com relação às condições oferecidas ao estudante do curso noturno, ao significado de estudar à noite e trabalhar, à comparação entre cursos diurno e noturno e à equalização das oportunidades de estudo que o curso oferece ao estudante trabalhador e não trabalhador.

Aspectos relacionados à biblioteca, aos laboratórios, às salas de aula e aos equipamentos, além de espaços de convivência, como cantina, centro acadêmico e áreas de vivência, podem se constituir como motivadores ou não para que o estudante deseje frequentar a instituição de ensino (TERRIBILI FILHO, 2004).

Para os estudantes participantes deste estudo, o curso noturno ainda parece estar deslocado dentro da Faculdade de Odontologia, com pouca integração à vida acadêmica e distante do curso diurno. Estudantes que mudaram para o curso de período integral demonstraram satisfação com a possibilidade de participar de atividades acadêmicas extracurriculares.

\footnotetext{
Acho bem dividido, sim, o diurno e o noturno. Isto não é bom porque é odontologia, e parece que ao invés de ser o curso de odontologia é o diurno e o noturno. Aliás, é o contrário, parece que é o noturno e a odonto. Parece que é separado assim. (Estudante 15)
}

Os professores, da mesma forma, observaram diferenças entre a vida acadêmica dos cursos diurno e noturno, percebendo uma dificuldade de participação e integração do estudante do noturno nas diferentes atividades oferecidas pela Universidade. 
Eu acho que eles ficam muito reduzidos, pelo menos aqueles que de fato trabalham, que não têm tempo de vir durante o dia, eles ficam um pouco mais isolados à noite, me dá essa sensação, [...] muitas das atividades da universidade, eu acho que o aluno, pelo menos que trabalha, ele tem dificuldade de se inserir. Mobilidade acadêmica, alguns eventos, acho que eles ficam mais reduzidos. (Professor 5)

Ao tratarem da integração entre os dois cursos, os professores demonstraram preocupação com o papel do curso noturno na instituição, o qual foi proposto com o objetivo de inserir o estudante trabalhador que quer cursar Odontologia e não tem a possibilidade de frequentar um curso de período integral.

[...] é um contexto diferente, são alunos diferentes, mas não sei se a instituição poderia fažer alguma coisa diferente do que já está sendo feito, a não ser esta questão de que todo mundo tem que se dar conta de que esse curso noturno existe, de que ele é igual ao curso diurno, que é o mesmo corpo docente, e que a gente, talvez, a gente tenha que oferecer mais oportunidades para eles. (Professor 8)

Ainda em relação à instituição de ensino, os estudantes apontaram como dificuldades para seu desempenho no curso questões específicas da estrutura física da instituição (salas de aula sem iluminação adequada para a utilização de equipamento de projeção à noite), a organização dos horários das disciplinas (disciplinas com grande carga horária concentrada em um único dia da semana) e a matrícula anual e não semestral nas disciplinas do curso noturno. Essa característica do curso faz com que os estudantes que reprovam tenham que esperar transcorrer um semestre inteiro para poder fazer a disciplina novamente.

Além de oferecer um curso desafiador e significativo para o estudante, a universidade deve comprometer-se com a melhoria permanente das estratégias de ensino-aprendizagem e contemplar programas contínuos que auxiliem os estudantes a identificar usos para as habilidades e os conhecimentos que eles desenvolveram durante a graduação (SON; COTTER; JOY, 2011).

Entre os estudantes que saíram do curso noturno, o principal motivo relatado para sua evasão foi o tempo de duração de oito anos (16 semestres), considerado muito longo quando comparado ao curso diurno de Odontologia da mesma instituição, que tem a duração de cinco anos (10 semestres). "Com certeza, eu só troquei para o dia porque é um curso mais curto, só por isso, só por isso. (Estudante 11)”. Os estudantes entrevistados neste estudo e que evadiram do curso noturno estão, atualmente, cursando Odontologia no curso diurno da UFRGS e apresentavam bom desempenho acadêmico no curso noturno. 
Essa mudança sugere a segurança dos estudantes pela escolha da formação profissional, conforme dados encontrados na caracterização do perfil dos estudantes ingressantes neste curso, turmas de 2010 a 2012, dos quais 81,8\% sentiam-se seguros ou completamente seguros em relação à escolha profissional (SOUZA; WESCHENFELDER; TOASSI, 2014). São estudantes que readaptaram sua trajetória na Universidade, de acordo com suas condições e disponibilidade de tempo para dedicar-se aos estudos.

Para o estudante, a mobilidade de um curso para outro pode ser considerada uma evasão positiva, visto que, em razão de seu amadurecimento na instituição, ele tem condições de direcionar melhor sua formação (VELOSO; ALMEIDA, 2002). Também Ristoff (1999) defende a ideia de que a saída de um curso para outro não se caracteriza como uma evasão negativa, uma exclusão, já que o estudante não abandonou o Ensino Superior, mas sim, fez uma adaptação, um investimento na busca de sucesso ou felicidade.

\section{ESTRATÉGIAS PARA A PERMANÊNCIA DO ESTUDANTE NO CURSO NOTURNO}

A redução no tempo de formação foi a estratégia mais citada entre os estudantes e professores para promover a permanência no curso noturno. Para isso, sugeriram aulas aos sábados, oferecendo a possibilidade de o aluno cursar, no semestre seguinte, a disciplina em que foi reprovado, oferta de disciplinas utilizando a modalidade da educação a distância ou durante o período das férias acadêmicas.

Foi sugerido, também, que a organização dos horários das disciplinas com maior carga horária fosse repensada de forma a possibilitar um melhor aproveitamento por parte dos estudantes. Nesse sentido, o horário das disciplinas poderia ser dividido em dias diferentes para aulas teóricas e aulas práticas, ou dar prioridade às disciplinas com maior carga horária para o início da semana.

Outro aspecto abordado pelos entrevistados como facilitador da permanência no curso foi a possibilidade de o estudante poder fazer a disciplina em que reprovou no próximo semestre, seja pela mudança de matrícula anual para semestral ou pela possibilidade de o estudante cursar a disciplina no turno inverso, desde que haja vaga nas turmas do curso diurno, para que o conteúdo visto em um semestre possa ser revisado e recuperado no semestre seguinte.

A realização de outras atividades acadêmicas, além das atividades de ensino de caráter obrigatório, foi citada como enriquecedora da formação e facilitadora da permanência no curso, porém a falta de 
tempo dos estudantes para participar e, também, o número reduzido de atividades ofertadas à noite foram aspectos destacados nas falas dos entrevistados. Nesse sentido, estudantes e professores recomendam que a oferta de atividades voltadas para pesquisa e extensão possam também contemplar os estudantes do curso noturno dentro do horário em que eles estão na faculdade ou aos sábados.

A permanência no curso também foi associada por estudantes e professores a aspectos relacionados à estrutura física e ao funcionamento do curso noturno e da Faculdade de Odontologia como um todo, tais como a ampliação do horário de funcionamento da biblioteca, do diretório acadêmico e da lanchonete, oferta de armários para guardar o instrumental do aluno desde os semestres iniciais do curso, mais iluminação no prédio e melhor funcionamento dos computadores disponíveis nas salas de aula.

Por fim, os professores destacaram a necessidade de continuar acompanhando o curso noturno para identificar suas necessidades, avaliar possíveis mudanças e promover seu desenvolvimento, tendo em vista a particularidade do ensino clínico voltado ao atendimento de pacientes, que o diferencia de outros cursos ofertados no turno da noite que não possuem essa característica.

\section{CURSO NOTURNO DE ODONTOLOGIA: TRAJETÓRIA ACADÊMICA EM CONSTRUC̣ÃO}

O curso noturno de Odontologia da UFRGS está inserido no contexto da política de expansão e reestruturação do Ensino Superior. É um curso recente, que ainda não possui nenhuma turma de concluintes e a trajetória acadêmica de seus estudantes está sendo construída a cada semestre.

No período de 2010 a fevereiro de 2014, o curso apresentou um número de estudantes fora da seriação aconselhada, principalmente por reprovação em uma ou mais disciplinas, que merece destaque. Já entre os estudantes que evadiram do curso noturno, grande parte optou por seguir o curso diurno de Odontologia da mesma instituição, caracterizando uma evasão aparente.

Estudantes e professores entendem que as experiências de retenção e evasão no curso noturno de Odontologia estão ligadas: a) à chegada e adaptação do estudante à rotina universitária, o que exigiu a construção de novas rotinas de estudo; b) à conciliação entre estudo e trabalho e à superação do cansaço após o dia de trabalho para dedicar-se aos estudos; c) à importância de vivências didáticopedagógicas mais dinâmicas, que incentivem a participação dos 
estudantes e favoreçam a aprendizagem; d) a um processo de avaliação voltado para a aprendizagem do estudante; e) ao papel da instituição de ensino no que se refere à distribuição e organização de horários das disciplinas, oferta anual de atividades de ensino obrigatórias, ao distanciamento entre cursos diurno e noturno e, de modo especial, ao tempo de duração do curso, considerado muito longo.

Os achados desta pesquisa sinalizam a necessidade de ações compartilhadas entre gestores, professores e estudantes que promovam a permanência dos estudantes no curso noturno de Odontologia, tais como redução no tempo estabelecido para sua conclusão, oferta semestral das disciplinas obrigatórias, adequação da organização e distribuição dos horários das disciplinas na carga horária semanal, maior integração do curso noturno ao diurno e às atividades acadêmicas da universidade. Melhorias no espaço físico, relatadas por estudantes e professores, também devem ser consideradas.

\section{REFERÊNCIAS}

AL-AMRI, M. et al. Significance of primary factors influencing students' performance at the College of Dentistry, King Saud University, Saudi Arabia. J. Pak Med. Assoc., Karachi, v. 62, n. 8, p. 816-821, Aug. 2012.

ALMEIDA, L. S.; SOARES, A. P. Os estudantes universitários: sucesso escolar e desenvolvimento psicossocial. In: MERCURI, E.; POLYDORO, S. A. J. (Org.). Estudante universitário: características e experiências de formação. Taubaté: Cabral, 2003.p. 15-40.

ASSOCIAÇÃO NACIONAL DOS DIRIGENTES DAS INSTITUIÇÕES FEDERAIS DE ENSINO SUPERIOR - ANDIFES. Diplomação, retenção e evasão nos cursos de graduação em Instituições de Ensino Superior públicas. NDIFES/ABRUEM/SESu/ MEC, 1996.

ARROYO, M. G. A universidade, o trabalhador e o curso noturno. Univ. Soc., Brasília, v. 1, p. 25-32, fev. 1991.

ARROYO, M. G. Políticas educacionais e desigualdades: à procura de novos significados. Educ. Soc., Campinas, v. 31, n. 113, p. 1381-1416, 2010.

ARROYO, M. G. Imagens quebradas: trajetórias e tempos de alunos e mestres. 8. ed. Petrópolis-RJ: Vozes, 2014.

BARDIN, L. Análise de conteúdo. São Paulo: Ed. 70, 2011.

BARREIRO, I. M. F; TERRIBILLI FILHO, A. Educação superior no período noturno: políticas, intenções e omissões. Ensaio: aval. pol. públ. educ., Rio de Janeiro, v. 15, n. 54, p. 81-102, jan./mar. 2007.

BITTAR, M.; ALMEIDA, C. E. M.; VELOSO, T. C. M. A. Políticas de educação superior: ensino noturno como estratégia de acesso para o estudante trabalhador. Educ. Quest., Natal, v. 33, n. 19, p. 279-304, set./dez. 2008.

BORDENAVE, J. D.; PEREIRA, A. M. Estratégias de ensino-aprendizagem.30. ed. Petrópolis, RJ: Vozes, 2010. 
BRAID, L. M. C.; MACHADO, M. D. F. A. S.; ARANHA, A. C. Estado da arte das pesquisas sobre currículo em cursos de formação de profissionais da área da saúde: um levantamento a partir de artigos publicados entre 2005 e 2011. Interface comun. saúde educ., Botucatu, v.16, n. 42, p. 679-692, 2012.

BRASIL. Institui as Diretrizes Curriculares Nacionais do Curso de Graduação em Odontologia. Resolução CNE/CES n. 3/2002, de 19 de fevereiro de 2002. Diário Oficial da União, Brasília, 04 mar. 2002. Seção 1, p. 10.

BRASIL. Ministério da Educação. REUNI Reestruturação e Expansão das Universidades Federais: Diretrizes Gerais. Brasília, 2007.

BRASIL. Presidência da República. Lei n. 12.711, de 29 de agosto de 2012. Dispõe sobre o ingresso nas universidades federais e nas instituições federais de ensino técnico de nível médio e dá outras providências. Diário Oficial da União, Brasília, 30 ago. 2012. Seção 1, p. 1.

BUENO, D. et al. Coordenação da formação, dos saberes e das políticas públicas: uma forma de trabalhar a evasão e a retenção na universidade. Porto Alegre: PROGRADUFRGS, 2011. 27 p.

CARDOSO, C. B. Efeitos da política de cotas na Universidade de Brasília: uma análise do rendimento e da evasão. 2008. 134 f. Dissertação (Mestrado em Educação) Faculdade de Educação, Universidade de Brasília, Brasília, 2008.

CAVALCANTI, A. L. et al. Motivos de ingresso e de evasão dos acadêmicos de odontologia de uma instituição pública. Rev. Odontol. UNESP, Araraquara, v. 39, n. 2, p. 95-99, mar./ abr. 2010.

COSTA, D. M.; COSTA, A. M.; BARBOSA, F. V. Financiamento público e expansão da educação superior federal no Brasil: o REUNI e as perspectivas para o REUNI 2. Rev. GUAL, Florianópolis, v. 6, n. 1, p. 106-127, 2013.

CUNHA, S. M.; CARRILHO, D. M. O processo de adaptação ao ensino superior e o rendimento acadêmico: adaptação e rendimento acadêmico. Psicol. Esc. Educ., Campinas, v. 9, n. 2, p. 215-222, 2005.

DONOSO, S.; SCHIEFELBEIN, E. Análisis de los modelos explicativos de retención de estudiantes en la universidad: una visión desde la desigualdad social. Estud. Pedagóg., Valdívia, v. 33, n. 1, p. 7-27, 2007.

FAGUNDES, N. C.; BURNHAM, T. F. Discutindo a relação entre espaço e aprendizagem na formação de profissionais de saúde. Interface comun. saúde educ., Botucatu, v. 9, n. 16, p. 105-114, 2005.

FAÚNDEZ, F; MUÑOZ, K.; CORNEJO, F. Percepción sobre el modelo educativo basado en competencias y su contribuición a la retención de estudiantes de la universidad de Talca. In: CONFERENCIA LATINOAMERICANA SOBRE EL ABANDONO EN LA EDUCACIÓN SUPERIOR, 2., 2012, Porto Alegre. Anais... Porto Alegre: PUC-RS, 2012. p. 738-744.

FEUERWERKER, L.; ALMEIDA, M. Diretrizes curriculares e projetos pedagógicos: é tempo de ação! Rev. ABENO, Brasília, v. 4, n. 1, p. 14-16, 2004.

FONTANELLA, B. J. B.; RICAS, J.; TURATO, E. R. Amostragem por saturação em pesquisas qualitativas em saúde: contribuições teóricas. Cad. saúde pública, Rio de Janeiro, v. 24, n.1, p. 17-27, 2008.

FREITAS, K. S. Alguns estudos sobre evasão e persistência de estudantes. Eccos Rev. Cient., São Paulo, v. 11, n. 1, p. 247-264, jan./jun. 2009.

GIL, A. C. Didática do ensino superior. São Paulo: Atlas, 2010. 
GOMES, M. J. et al. Evasão acadêmica no ensino superior: estudo na área da saúde. Rev. bras. pesqui. saúde, Vitória, v. 12, n. 1, p. 6-13, 2010.

KELLER-FRANCO, E.; MASETTO, M. T. Currículo por projetos no ensino superior: desdobramentos para a inovação e qualidade na docência. Rev. Triângulo (Online), Uberaba, v. 5, n. 2, p. 3-21, 2012. Disponível em: <http://seer.uftm.edu.br/revistaeletronica/ index.php/revistatriangulo/article/view/377/pdf>. Acesso em: 23 fev. 2017.

MACEDO, A. R. et al. Educação superior no século XXI e a reforma universitária brasileira. Ensaio: aval. pol. públ. educ, Rio de Janeiro, v. 13, n. 47, p. 127-148, 2005.

MASETTO, M. Inovação na Educação Superior. Interface comun. Saúde educ., Botucatu, v. 8 , n. 14 , p. $197-202,2004$.

MÉNDÉZ, J. M. Á. Avaliar a aprendizagem em um ensino centrado nas competências. In: SACRISTÁN, J. G. et al. Educar por competências. Porto Alegre: Artmed, 2011. p. 233-264. MINAYO, M. C. S. O desafio do conhecimento: pesquisa qualitativa em saúde. 12. ed. São Paulo: Hucitec, 2009.

MORA, J. C de. et al. Aceptación de la institución universitaria desde el punto de vista del alumnado. Arquivos analíticos de políticas educativas, Tempe, v. 23, n. 3, p. 1-24, 2015.

MORIN, E. Os sete saberes necessários à educação do futuro. 2. ed. São Paulo: Cortez, 2000.

MORITA, M. C.; KRIGER, L. Mudanças nos cursos de odontologia e a interação com o SUS. Rev. ABENO, Brasília, v. 4, n. 1, p. 17-21, 2004.

NEVES, C. E. B.; RAIZER, L.; FACHINETTO, R. F. Acesso, expansão e equidade na educação superior: novos desafios para a política educacional brasileira. Sociologias, Porto Alegre, v. 9, n. 17, p. 124-157, jan./jun. 2007.

POLYDORO, S. A. J. et al. Desenvolvimento de uma escala de integração ao ensino superior. Psico USF, Bragança Paulista, v. 6, n. 1, p. 11-17, 2001.

RISTOFF, D. A tríplice crise da universidade. In: TRINDADE, H. (Org.). Universidade em ruínas na república dos professores. Petrópolis: Vozes, 1999.

ROBERTO, R. F. O programa de apoio a planos de reestruturação e expansão das universidades federais: o caso REUNI na Universidade Federal de Viçosa. Rev. Adm. Pública Gestão Soc. - APG, Viçosa, v. 3, n. 3, p. 300-323, jul./set. 2011.

SACRISTÁN, J. G. O currículo: uma reflexão sobre a prática. Porto Alegre: Artmed, 2000.

SALIBA, N. A. et al. Organização curricular, evasão e repetência no curso de odontologia: um estudo longitudinal. Rev. Odontol. UNESP, Araraquara, v. 35, n. 3, p. 209-214, 2006.

SANTOS, B. L. P. A representação do REUNI no debate do ensino superior enquanto direito. Educ. rev., Belo Horizonte, v. 10, n. 1, p. 29-44, 2009.

SCHWARTZMAN, S. A questão da inclusão na Universidade Brasileira. In: M. C. L. Peixoto; A. V. Aranha (Org.). Universidade pública e inclusão social: experiência e imaginação. Minas Gerais: UFMG, 2008.

SILVA, E. T. et al. Factors influencing students' performance in a brazilian dental school. Braz. Dent. J., Ribeirão Preto, v. 2, n. 1, p. 80-86, 2010.

SILVA FILHO, R. L. L. et al. A evasão no ensino superior brasileiro. Cad. Pesqui., São Paulo, v. 37, n. 132, p. 641-659, set./dez. 2007.

SOARES, M. L. A.; SAMPAIO, S. M. R. Reflexões acerca de ser um estudante trabalhador em uma universidade pública brasileira. Revista Congreso Universidad, La Habana, v. 2, n.2, p. 1-9, 2013. 
SOUZA, J. M.; WESCHENFELDER, H. C.; TOASSI, R. F. C. Expansão da educação superior no Brasil a partir do REUNI: o curso noturno de Odontologia da Universidade Federal do Rio Grande do Sul. Rev. GUAL, Florianópolis, v. 7, n. 1, p. 63-78, 2014.

SOUZA, S. A.; REINERT, J. N. Avaliação de um curso de ensino superior através da satisfação/insatisfação discente. Avaliação, Campinas, v. 15, n. 1, p. 159-176, mar. 2010.

TEIXEIRA, M. A. P. et al. Adaptação à universidade em jovens calouros. Rev. semest. assoc. bras. psicol. esc. educ. (ABRAPEE), São Paulo, v. 12, n. 1, p. 185-202, jan./jun. 2008.

TERRIBILI FILHO, A. Ensino superior noturno no Brasil: as dificuldades do entorno educacional e a importância do relacionamento social no ambiente educacional. Educação (UFSM), Santa Maria, v. 29, n. 1, p. 21-36, 2004.

TERRIBILI FILHO, A. Ensino superior noturno no Brasil: estudar para trabalhar ou trabalhar para estudar? Pensam. real., São Paulo, v. 11, n. 22, p. 43-65, 2008.

TERRIBILI FILHO, A.; NERY, A. C. B. Ensino superior noturno no Brasil: história, atores e políticas. RBPAE, Goiânia, v. 25, n. 1, p. 61-81, 2009.

TOASSI, R. F. C. et al. Currículo integrado no ensino de Odontologia: novos sentidos para a formação na área da saúde. Interface comun. saúde educ., Botucatu, v. 16, n. 41, p. 529542, abr./jun. 2012.

TRIGUEIRO, M. G. S. Reforma universitária e mudanças no ensino superior no Brasil. Brasília: UNESCO, 2003.

UNIVERSIDADE FEDERAL DO RIO GRANDE DO SUL - UFRGS. Resolução n. 9/2003, de 19 de março de 2003. Regulamenta o ordenamento de matrícula. Disponível em: <http://www.ufrgs.br/cepe/legislacao/resolucoes-normativas/resolucao-no-09-2003de-19-03-2003>. Acesso em: 27 jan. 2016.

UNIVERSIDADE FEDERAL DO RIO GRANDE DO SUL - UFRGS. Projeto Político Pedagógico do Curso Diurno de Odontologia. Porto Alegre, 2014a. Disponível em: $<$ http://www.ufrgs.br/odontologia/ensino/odonto/graduacao/projeto-pedagogico-docurso-diurno/view>. Acesso em: 25 jan. 2016.

UNIVERSIDADE FEDERAL DO RIO GRANDE DO SUL - UFRGS. Projeto Político Pedagógico do Curso Noturno de Odontologia. Porto Alegre, 2014b. Disponível em: <http://www.ufrgs.br/odontologia/ensino/odonto/graduacao/projeto-pedagogico-docurso-noturno/view>. Acesso em: 27 jan. 2016.

VARGAS, H. M.; PAULA, M. F. C. A inclusão do estudante-trabalhador e do trabalhador estudante na educação superior: desafio público a ser enfrentado. Avaliação, Campinas, v. 18, n. 2, p. 459-485, jul. 2013.

VELOSO, T. C. M. A.; ALMEIDA, E. P. Evasão nos cursos de graduação na Universidade Federal de Mato Grosso, campus universitário de Cuiabá - um processo de exclusão. Sér. Estud. Per. Mestr. Educ. UCDB,, Campo Grande, n. 13, p. 133-148, jan./jun. 2002.

VIDALES, S. El fracaso escolar em la educación media superior. El caso del bachillerato de una universidad mexicana. Rev. iberoamericana calidad, eficacia cambio educ., Madri, v. 7, n. 4, p. 321-341, 2009.

WILLCOXSON, L.; COTTER, J.; JOY, S. Beyond the first-years experience: the impact on attrition of student experiences throughout undergraduate degree studies in six diverse universities. Stud. high. educ, Dorchester on Thames, v. 36, n. 3, p. 331-352, May 2011.

YEPES, F.L. et al. Factores causales de la deserción estudiantil en el pregrado de la Facultad de Odontología de la Universidad de Antioquia de 1997 a 2004. Rev. fac. odontol. univ. antioq., Medelin, v. 19, n. 1, p. 35-48, 2007. 
YIN, R. K. Estudo de caso: planejamento e métodos. 4. ed. Porto Alegre: Bookman, 2010. ZAGO, N. Do acesso à permanência no ensino superior: percursos de estudantes universitários de camadas populares. Rev. bras. educ., Belo Horizonte, v. 11, n. 32, p. 226-237, 2006.

\section{NOTAS}

${ }^{1}$ A pesquisa teve a aprovação do Comitê de Ética em Pesquisa (CEP) da Universidade (CAAE 12567113.8.0000.5347 - parecer no 241.514).

${ }^{2}$ Statistical Package for Social Science (SPSS $\left.®\right)$. Statistical Analysis Using SPSS. Chicago, 2001.

${ }^{3}$ Visual Qualitative Data (ATLAS.tiß). Scientific Software Development. Berlin, 1997.

Submetido: 22/09/2015

Aprovado: 16/02/2016

Contato:

Juliana Maciel de Souza Lamers

Universidade Federal do Rio Grande do Sul (UFRGS), Faculdade de Odontologia

Rua Ramiro Barcelos, n. 2492. Bairro Santa Cecília

Porto Alegre |RS | Brasil

CEP. 90.035-003 